\title{
SKRINING FITOKIMIA DAN PENETAPAN KADAR FENOL TOTAL PADA EKSTRAK DAUN NANGKA (Artocarpus heterophyllus), CEMPEDAK (Artocarpus integer), dan TARAP (Artocarpus odoratissimus) ASAL DESA PENGARON KABUPATEN BANJAR
}

\author{
Muhammad Ikhwan Rizki*, Nurlely, Fadlilaturrahmah, Ma'shumah \\ Program Studi Farmasi FMIPA Universitas Lambung Mangkurat \\ *: ikhwanrizki@ulm.ac.id
}

\begin{abstract}
ABSTRAK
Daun nangka (Artocarpus heterophyllus), cempedak (Artocarpus integer), dan tarap (Artocarpus odoratissimus) digunakan secara empiris oleh masyarakat Desa Pengaron Kabupaten Banjar untuk mengobati antimalaria, antidiabetes, nyeri perut, dan penanganan kanker. Metabolit sekunder golongan fenol bertanggungjawab terhadap berbagai aktivitas tanaman. Penelitian ini bertujuan untuk mengetahui golongan senyawa dan kadar fenol total pada daun nangka ( $A$. heterophyllus), cempedak (A. integer), dan Tarap (A. odoratissimus). Sampel daun dikeringkan menggunakan oven, kemudian serbuk daun diekstraksi menggunakan etanol. Dilakukan skrining fitokimia pada ekstrak menggunakan pereaksi, kemudian penetapan kadar fenol ditentukan dengan spektrofotometer UV-Vis. Hasil penelitian menunjukkan bahwa pada ekstrak daun nangka (A. heterophyllus), cempedak (A. integer), dan tarap (A. odoratissimus) mengandung senyawa golongan fenol, flavonoid, dan tanin. Kadar fenol total ekstrak etanol daun $A$. heterophyllus, A. integer dan A. odoratissimus berturut-turut sebesar 13,174 \pm 1,378 $\mathrm{mgGAE} /$ gram ekstrak, 37,204 \pm 2,202 mgGAE/gram ekstrak dan 35,886 \pm $0,890 \mathrm{mgGAE} / \mathrm{gram}$ ekstrak.
\end{abstract}

Kata Kunci: Artocarpus heterophyllus, Artocarpus integer, Artocarpus odoratissimus, fenol total, skrining fitokimia

\section{ABSTRACT}

The leaves of jackfruit (Artocarpus heterophyllus), cempedak (Artocarpus integer), and tarap (Artocarpus odoratissimus) are used empirically by the people of Desa Pengaron, Banjar Regency for treat antimalarials, antidiabetic, abdominal pain, and cancer. The secondary metabolites of the phenol group are responsible for various plant activities. This study aims to determine of compounds and total phenol content in leaves of jackfruit (A. heterophyllus), cempedak (A. integer), and tarap (A. odoratissimus). The leaf samples were oven-dried, then the leaf powder was extracted using ethanol. Phytochemical screening was carried out on the extract using reagents, and phenol content was determined using a spectrophotometer UV-Vis. The results showed that the extracts of leaves jackfruit (A. heterophyllus), cempedak (A. integer), and tarap (A. odoratissimus) contained phenol, flavonoids, and tannins. Total phenol content of leaves A. heterophyllus, A. integer and A. odoratissimus were 13,174 $\pm 1,378 \mathrm{mgGAE} /$ gram extract, 37,204 $\pm 2,202 \mathrm{mgGAE} /$ gram extract, and 35,886 $\pm 0.890 \mathrm{mgGAE} /$ gram extract. Keywords: Artocarpus heterophyllus, Artocarpus integer, Artocarpus 
odoratissimus, total phenol, phytochemical screening

\section{PENDAHULUAN}

Nangka (A. heterophyllus), cempedak (A. integer), dan Tarap (A. odoratissimus) adalah tanaman yang banyak terdapat di Kalimantan. Daun tanaman tersebut banyak digunakan secara empiris oleh masyarakat Desa Pengaron Kabupaten Banjar untuk mengobati antimalaria, antidiabetes, nyeri perut, dan penanganan kanker ${ }^{1,2,3,4,5}$. Cempedak merupakan salah satu jenis tanaman asli Indonesia $^{6}$. Getah, kulit, daun dan akar dari beberapa jenis Artocarpus dapat dijadikan obat ${ }^{7}$. Ekstrak kulit batang nangka pada uji fitokimia mengandung senyawa fenol, senyawa tanin dan vitamin $\mathrm{C}^{8}$. Ketiga tanaman daun A. heterophyllus Lamk., A. integer (Thunb.) Merr., dan A. odoratissimus diteliti merupakan satu genus Artocarpus. Daun dari cempedak dan tarap belum banyak diteliti.

Skrining fitokimia yaitu identifikasi golongan metabolit sekunder yang terkandung pada tumbuhan atau bahan alam. Skrining fitokimia umumnya merupakan identifikasi awal dalam menentukan golongan senyawa. Skrining fitomikia identik dengan identifikasi golongan senyawa menggunakan pereaksi dengan menempatkan sampel cair pada tabung reaksi ${ }^{9}$.

Senyawa bahan alam golongan fenol telah diketahui memiliki efek antioksidan ${ }^{10}$. Golongan fenol dapat menghambat reaksi peroksidasi dalam tubuh, sehingga dapat mencegah terjadinya berbagai penyakit kronis seperti diabetes, kanker, dan gangguan hati ${ }^{11}$. Penelitian ini bertujuan untuk mengetahui golongan senyawa dan kadar fenol total pada daun nangka ( $A$. heterophyllus), cempedak (A. integer), dan Tarap (A. odoratissimus).

\section{METODE PENELITIAN}

1. Alat dan Bahan

Alat yang digunakan pada penelitian ini yaitu alat-alat gelas (Pyrex® Iwaki Glass), blender, cawan porselen, corong pisah, neraca analitik (Ohaus®), pengayak No. 30, propipet, 
rak tabung reaksi, rotary vacuum evaporator (Heidolph), sendok besi, spektrofotometer UV-Vis (Spectronic Genesys $\left.{ }^{\circledR} 10 \mathrm{uv}\right)$, stopwatch, rotary evaporator, waterbath $\left(\mathrm{SMIC}^{\circledR}\right)$ dan vortex mixer

Bahan yang digunakan yaitu daun A. heterophyllus, A. integer, A. odoratissimus, akuades, pelarut etanol $70 \%$, asam galat, Pereaksi Folin Ciocalteau 7,5\%, $\mathrm{Na} 2 \mathrm{CO} 31 \mathrm{M}$, aluminium foil dan kertas saring.

\section{Prosedur Penelitian}

\section{A. Pembuatan Ekstrak}

Sampel daun diambil pada pagi hari. Dilakukan perajangan agar daun mudah dikeringkan. Selanjutnya dilakukan pengeringan daun dengan oven suhu dijaga 500C. Selanjutnya dilakukan penyerbukan terhadap simplisia kering yang diperoleh ${ }^{12}$. Simplisia kering kemudian dihaluskan dengan blender, lalu diayak menggunakan pengayak no. $40^{13}$.

Serbuk simplisia ditimbang kemudian diekstraksi dengan metode maserasi menggunakan etanol $70 \%$ (perbandingan 1:5) selama 24 jam dengan remaserasi dua kali. Ekstrak cair dipisahkan dari residu menggunakan kertas saring Whatman No.1. Maserat diuapkan dengan vacuum rotary evaporator, kemudian diuapkan di atas waterbath hingga diperoleh ekstrak kental ${ }^{13}$.

\section{B. Skrining Fitokimia}

Skrining fitokimia dilakukan dengan metode tabung untuk identifikasi senyawa golongan fenol menggunakan $\mathrm{FeCl} 31 \%$, flavonoid menggunakan serbuk magnesium, alkaloid menggunakan pereaksi Dragendorff, tannin menggunakan $\mathrm{FeCl} 3$, saponin menggunakan aquades, terpenoid dan steroid menggunakan pereaksi Lieberman-Burchard ${ }^{14}$.

\section{Penentuan Kadar Fenol Total}

Dilakukan pembuatan seri konsentrasi asam galat sebagai standar untuk membuat persamaan kurva baku. Larutan asam galat dibuat dengan seri konsentrasi 20; 25; 30; 35; dan 40 ppm.

Sebanyak 0,5 mL larutan asam galat dimasukkan ke dalam tabung, ditambahkan 2,5 $\mathrm{mL}$ pereaksi Folin Ciocalteau 7,5\% kemudian digojog. Didiamkan 3 menit, ditambah $2 \mathrm{~mL}$ larutan $\mathrm{Na} 2 \mathrm{CO} 31 \mathrm{M}$ digojog homogen, didiamkan selama operating time. Diukur absorbansinya pada panjang gelombang maksimum, kemudian di 
buat kurva kalibrasi hubungan antara konsentrasi asam galat dengan absorbansi ${ }^{15,16}$.

Sebanyak $\quad 10 \quad \mathrm{mg}$ sampel dilarutkan dalam $10 \mathrm{~mL}$ aquades, kemudian diencerkan sehingga konsentrasinya menjadi 100 ppm. Larutan tersebut kemudian diperlakukan sama seperti larutan standar. Absorbansi sampel selanjutnya diintegrasikan pada persamaan kurva baku asam galat ${ }^{17}$.

\section{HASIL DAN PEMBAHASAN}

1. Hasil Determinasi Tanaman

Determinasi tanaman dilakukan di Badan Penelitian dan Pengembangan Daerah Kebun Raya Banua Provinsi Kalimantan Selatan. Hasil determinasi berdasarkan Surat No. 050/341-LIT/KRB tertanggal 25 Juni 2019 diketahui bahwa ketiga sampel yang diujikan yaitu Nangka (Artocarpus heterophyllus), cempedak (Artocarpus integer), dan Tarap (Artocarpus odoratissimus). Daun yang digunakan pada penelitian ini dapat dilihat pada gambar di bawah ini.

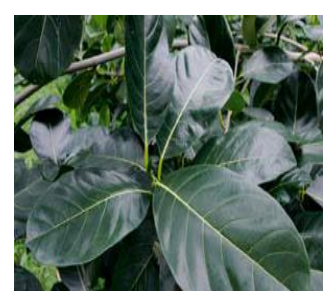

(a)

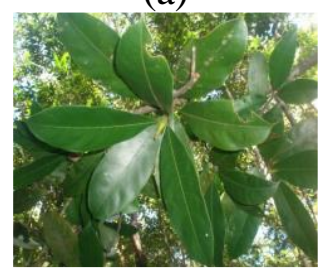

(b)

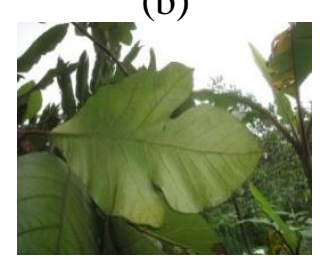

(c)

Gambar 1. Daun (a) nangka, (b) cempedak, dan (c) tarap

\section{Hasil Ekstraksi}

Serbuk simplisia yang didapatkan dari ketiga daun sama yaitu berwarna hijau, tidak berasa, dan tidak berbau. Filtrat hasil maserasi dikumpulkan dan diuapkan di atas waterbath hingga bobotnya tetap dengan ekstrak kental daun nangka ( $A$. heterophyllus) sebanyak 18,02 gram, daun cempedak (A. integer) sebanyak 26,29 gram, dan daun tarap (A. odoratissimus) sebanyak 26,11 gram berwarna hijau. Hasil ekstraksi diperoleh ekstrak kental yang dapat dihitung rendemennya pada Tabel 1.

Tabel 1. Rendemen Ekstrak Daun Nangka, Cempedak, dan Tarap

\begin{tabular}{|l|l|c|}
\hline No. & \multicolumn{1}{|c|}{ Sampel } & $\begin{array}{c}\text { Rendemen } \\
(\boldsymbol{\%})\end{array}$ \\
\hline 1. & Daun Nangka & 18,02 \\
\hline 2. & Daun Cempedak & 26,29 \\
\hline
\end{tabular}




\begin{tabular}{|l|l|l|}
\hline 3. & Daun Tarap & 26,11 \\
\hline
\end{tabular}

Selisih hasil persen rendemen yang didapatkan dipengaruhi oleh perbedaan pelarut yang digunakan. Tujuan perhitungan rendemen adalah untuk mengetahui persentase atau seberapa besar zat yang tersari dalam pelarut yang digunakan, sehingga dapat menentukan berapa banyak ekstrak yang diperoleh dengan memperkirakan banyaknya serbuk yang digunakan 9 .

\section{Hasil Skrining Fitokimia}

Identifikasi dilakukan dengan uji reaksi warna. Hasil pengujian menggunakan pereaksi dapat dilihat pada Tabel 2

Tabel 2. Hasil Skrining Fitokimia Ekstrak Daun Nangka, Cempedak, dan Tarap tanaman satu genus tidak terdapat perbedaan golongan senyawa yang terkandung di dalamnya. Golongan fenol, flavonoid, dan tanin memiliki kemampuan antioksidan yang kuat. Ketiga golongan senyawa tersebut juga akan memberi pengaruh terhadap aktivitas dari daun genus Artocarpus.

Pada penelitian lain didapatkan ekstrak Artocarpus heterophyllus Lamk. mengandung metabolit sekunder flavonoid, tanin, dan saponin. Senyawa yang terkandung dalam Artocarpus integer (Thunb.) Merr. yaitu flavonoid, fenol, dan heteriflavon $\mathrm{C}^{1}$.

4. Hasil Penetapan Kadar Fenol Total

Penetapan kurva baku asam galat sebagai kuantifikasi yang \begin{tabular}{c|l|c|c|c|c|}
\hline No. & Golongan & Nangka & Cempedak & Tarap \\
\hline 1. & Fenol & + & + & + menggunakan standar eksternal dalam \\
\hline 2. & Flavonoid & + & + & + perhitungan kadar fenol total. Masing- \\
\hline 3. & Alkaloid & - & - & - \\
\hline 4. & Tanin & + & + & + masing konsentrasi seri kadar asam \\
\hline 5. & Saponin & - & - & - \\
\hline 6. & Terpenoid & - & - & - galat diukur absorbansinya dan dibuat \\
\hline 7. & Steroid & - & - & - \\
\hline
\end{tabular} Hasil skrining fitokimia menunjukkan antara absorbansi (y) dan konsentrasi daun nangka, cempedak, dan tarap mengandung senyawa golongan fenol, (x)

flavnoid, dan tanin. Pada ketiga 


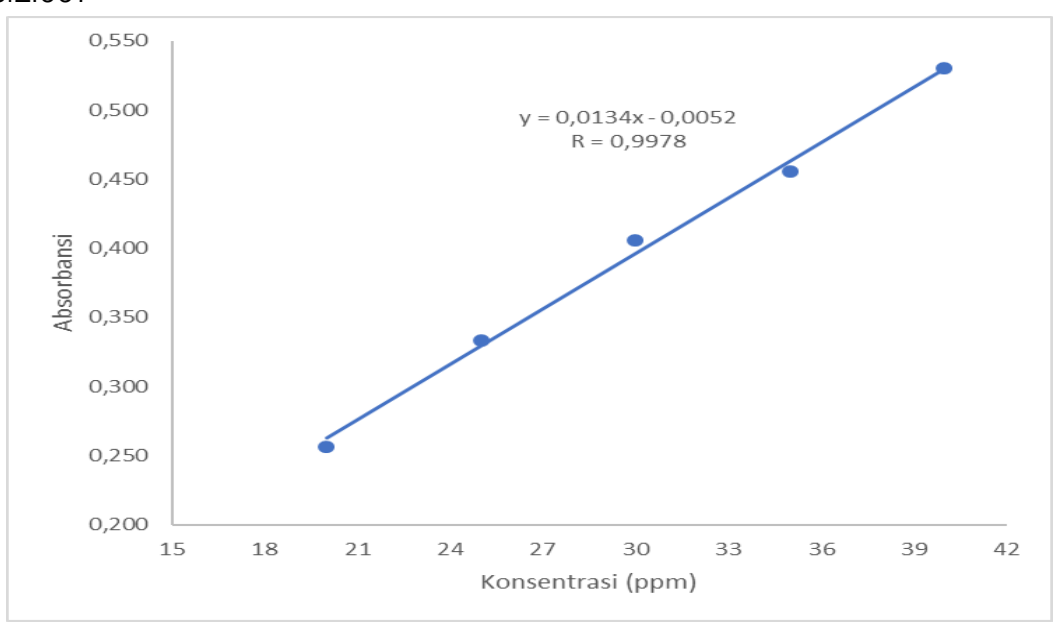

Gambar 2. Persamaan Kurva Baku Asam Galat

Persamaan kurva baku yang diperoleh adalah $\mathrm{y}=0,0134 \mathrm{x}+(-$ 0,0052) dengan nilai koefisien korelasi $\mathrm{r}=0,9978$. Nilai koefisien korelasi menunjukkan bahwa adanya hubungan yang linear antara konsentrasi dan absorbansi sebesar 99,78\%. Hasil nilai koefisien korelasi yang diperoleh telah memenuhi syarat linearitas yaitu $\geq 0,997^{4}$.

Pada pengukuran senyawa fenol total dibuat sebanyak tiga kali replikasi untuk keperluan akurasi data $^{18}$. Berdasarkan hasil penelitian ini diperoleh kadar fenol total ekstrak etanol daun A. heterophyllus, A. integer dan A. odoratissimus yang ditampilkan dalam

Tabel 3. Kadar Fenol Total Ekstrak Daun Nangka, Cempedak, dan Tarap

\begin{tabular}{|l|l|c|c|}
\hline No. & \multicolumn{1}{|c|}{ Sampel } & $\begin{array}{c}\text { Kadar } \\
(\mathbf{m g} / \mathbf{g}) \pm \mathbf{S D}\end{array}$ & $\begin{array}{c}\text { Persen } \\
\mathbf{( \% )}\end{array}$ \\
\hline 1. & Daun Nangka & $13,17 \pm 1,3$ & $1,31+0,1$ \\
\hline 2. & Daun & $37,20 \pm 2,2$ & $3,72+0,2$ \\
& Cempedak & & \\
\hline 3. & Daun Tarap & $25,88 \pm 0,8$ & $2,58+0,08$ \\
\hline
\end{tabular}

Kadar fenol total ekstrak etanol daun A. heterophyllus, A. integer dan A. odoratissimus berturut-turut sebesar $13,174 \pm 1,378 \mathrm{mgGAE} /$ gram ekstrak, $37,204 \pm 2,202 \mathrm{mgGAE} /$ gram ekstrak dan 35,886 $\pm 0,890 \mathrm{mgGAE} / \mathrm{gram}$ ekstrak. Penelitian Utami et al (2015) mendapatkan kadar fenol total daun sukun (Artocarpus altilis) dari ekstrak etanol cara refluks sebesar 52,67 mgGAE/gram ${ }^{19}$.

Faktor yang mempengaruhi perbedaan kadar fenol total pada suatu ekstrak salah satunya ialah faktor lingkungan. Perbedaan kandungan unsur hara, ketinggian wilayah, kelembaban serta intensitas cahaya matahari pada lokasi tumbuh tanaman berpengaruh terhadap senyawa metabolik sekunder yang ada pada tumbuhan ${ }^{20}$.

Fenolik adalah kategori terbanyak dari bidang fitokimia dan 
paling luas persebarannya dalam kingdom tanaman. Golongan fenolik ditandai dengan cincin benzena dengan gugus -OH yang terikat. Banyak golongan fenolik yang berperan sebagai pelindung kulit sebagai tabir surya, senyawa antimikroba, senyawa anti herbivora, dan antioksidan ${ }^{20}$. Senyawa fenol yang terkandung dalam ekstrak etanol daun A. heterophyllus, A. integer dan A. odoratissimus merupakan hasil metabolit sekunder yang potensial sebagai sumber bahan baku obat yang berperan sebagai antioksidan.

\section{KESIMPULAN}

Hasil penelitian menunjukkan bahwa pada ekstrak daun nangka ( $A$. heterophyllus), cempedak (A. integer), dan tarap (A. odoratissimus) mengandung senyawa golongan fenol, flavonoid, dan tanin. Kadar fenol total ekstrak etanol daun A. heterophyllus, A. integer dan A. odoratissimus berturut-turut sebesar $13,174 \pm 1,378$ mgGAE/gram ekstrak, 37,204 \pm 2,202 mgGAE/gram ekstrak dan 35,886 \pm 0,890 mgGAE/gram ekstrak.

\section{UCAPAN TERIMA KASIH}

Peneliti menguncapkan terimakasih kepada Universitas Lambung Mangkurat yang telah mendanai penelitian ini melalui Dana DIPA FMIPA Universitas Lambung Mangkurat.

\section{DAFTAR PUSTAKA}

1) Aty W, Zaini, \& Syafruddin, 2011, Mekanisme dan Aktivitas Antimalaria dari Senyawa Flavonoid yang Diisolasi dari Cempedak (Artocarpus champeden), JBP, Vol. 13 (2) : 6777.

2) Mohd F, Karim, \& Perisamy E, 2015, Comparison of Phytochemicals and Antioxidant Properties of Different Fruit Parts of Selected Artocarpus Species from Sabah, Malaysia, Sains Malaysiana. Vol. 44 (3) : 355-363.

3) Miss K. B, 2015, Skripsi Pengaruh Pemberian Ekstrak Etanol Daun Nangka (Artocarpus heterophyllus) Terhadap Penurunan Kadar Glukosa Darah Tikus Wistar Yang Diinduksi Aloksan, Fakultas Farmasi Universitas Muhammadiyah, Surakarta.

4) Haris D. C, 2010, Quantitative Chemical Analysis Eight Edition, W. H. Freeman and Company, New York.

5) Hasmalina $N \&$ Nasution M, 2013, Pengujian antiradikal bebas difenilpikril hidrazil (DPPH) ekstrak etil asetat daun nangka (Artocarpus heterophyllus Lamk). J. Sains Dasar, Vol. 3 (2) : 137 141.

6) Abdullah B, Diyono E, Syaefullah, Suyanti, \& Setyadjit, 2014, Optimalisasi Cara Pemeraman Buah Cempedak (Artocarpus champeden), Informatika Pertanian, Vol. 23 (1) : 35-46. 
7) Mody, L \& Suhartati, 2013, Potensi Pengembangan Cempedak (Artocarpus Integer Merr.) Pada Hutan Tanaman Rakyat Ditinjau Dari Sifat Kayu Dan Kegunaannya, Info Teknis EBONI, Vol. 10 (2) : 69-83.

8) Indiradewi H, 2015, Tesis Krim Ekstrak Etanol Kulit Batang Pohon Nangka (Arthocarpus heterophilus) Sama Efektifnya Dengan Krim Hidrokuinon Dalam Mencegah Peningkatan Jumlah Melanin Pada Kulit Marmut (Cavia porcelus) Yang Dipapar Sinar Uvb. Program Pascasarjana, Universitas Udayana, Denpasar.

9) Rizki, M.I, 2020, Farmakognosi dan Metabolit Sekunder, Penerbit CV. IRDH, Malang.

10) Iqbal $P$, Da'I $M, \&$ Utami $W$, 2008, Uji Aktivitas Antioksidan Buah Psidium guava L. Dengan Metode DPPH (1,1- Difenil-2Pikril Hidrazil) Serta Penetapan Kadar Fenolik dan Flavonoid, Pharmacon, Vol. 9 (2) : 52-56.

11) Sri W, 2011, Uji Aktivitas Antioksidan Ekstrak Etanol Akar, Kulit Batang Dan Daun Tanaman Sambiloto (Andrographis paniculata Ness.) Dengan Metode Linoleat - Tiosianat, Fitofarmaka, Vol. 1 (2) : 9-13.

12) BPOM RI, 2013, Pedoman Teknologi Formulasi Sediaan Berbasis Ekstrak Volume 2, Badan Pengawas Obat dan Makanan Republik Indonesia, Jakarta.

13) Depkes RI, 2008, Farmakope

Herbal Indonesia, Edisi I, Departemen Kesehatan Republik Indonesia, Jakarta.

14) Tiwari P., Kumar B, Kaur M, Kaur G, \& Kaur H, 2011, Phytochemical Screening and Extraction: A Review. Internationale

Pharmaceuticasciencia, 1: 98-106.

15) Anwar \& Triyasmono, 2016, Kandungan Total Fenolik, Total Flavonoid, dan Aktivitas Antioksidan Ekstrak Etanol Buah Mengkudu (Morinda citrifolia L.), Jurnal Pharmascience. 3: 83-92.

16) Alfian, R \& H. Susanti, 2012, Penetapan Kadar Fenolik Total Ekstrak Metanol Kelopak Bunga Rosella Merah (Hibiscus sabdariffa Linn) dengan Variasi Tempat Tumbuh Secara Spektrofotometri, Jurnal Ilmiah Kefarmasian. 2: 73-80.

17) Ayuchecaria N, Saputera M, Niah R, 2020, Penetapan Kadar Fenolik Total Ekstrak Batang Bajakah Tampala (Spatholobus littoralis Hassk.) Menggunakan Spektrofotometri UV-Visible, Jurnal Insan Farmasi Indonesia, 3 (1), Mei 2020, Hal 132-141

18) Ahmad A, Juwita R, Ratulangi $S$, \& Malik A, 2015, Penetapan Kadar Fenolik dan Flavonoid Total Ekstrak Metanol Buah dan Daun Patikala (Etlingera elatior (Jack) R.M.SM), Pharmaceutical Sciences and Research Vol. 2 (1): 1-10.

19) Utami R, Yuliawati K, Syafnir L, 2015, Pengaruh Metode Ekstraksi terhadap Aktivitas Antioksidan Daun Sukun (Artocarpus altilis(Parkinson) Fosberg), Prosiding Penelitian SPESIA Unisba 2015: 280 - 286.

20) Rizki M, 2020, Farmakognosi dan Metabolit Sekunder, Penerbit IRDH, Malang. 